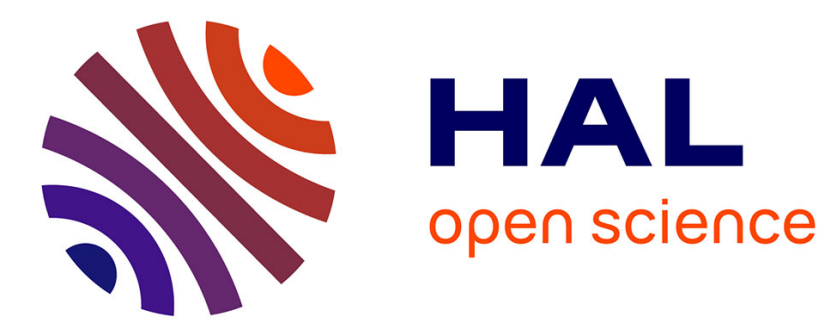

\title{
Long-Term Mitigation Strategies and Marginal Abatement Cost Curves: A Case Study on Brazil
}

Adrien Vogt-Schilb, Stéphane Hallegatte, Christophe de Gouvello

\section{To cite this version:}

Adrien Vogt-Schilb, Stéphane Hallegatte, Christophe de Gouvello. Long-Term Mitigation Strategies and Marginal Abatement Cost Curves: A Case Study on Brazil. World Bank Policy Research Working Papers, 2014, pp.6808. hal-00966821v2

\section{HAL Id: hal-00966821 https://hal-enpc.archives-ouvertes.fr/hal-00966821v2}

Submitted on 28 Apr 2014 (v2), last revised 30 Oct 2014 (v3)

HAL is a multi-disciplinary open access archive for the deposit and dissemination of scientific research documents, whether they are published or not. The documents may come from teaching and research institutions in France or abroad, or from public or private research centers.
L'archive ouverte pluridisciplinaire HAL, est destinée au dépôt et à la diffusion de documents scientifiques de niveau recherche, publiés ou non, émanant des établissements d'enseignement et de recherche français ou étrangers, des laboratoires publics ou privés. 


\title{
Long-Term Mitigation Strategies and Marginal Abatement Cost Curves: A Case Study on Brazil
}

\author{
Adrien Vogt-Schilb ${ }^{1,2, *}$, Stéphane Hallegatte ${ }^{2}$, Christophe de Gouvello ${ }^{3}$ \\ ${ }^{1}$ CIRED, Nogent-sur-Marne, France \\ ${ }^{2}$ The World Bank, Washington D.C., USA \\ ${ }^{3}$ The World Bank, Brasilia, Brazil
}

\begin{abstract}
Decision makers facing abatement targets need to decide which abatement measures to implement, and in which order. This paper investigates the ability of marginal abatement cost (MAC) curves to inform this decision, reanalyzing a MAC curve built for Brazil by 2030. Using MAC curves to design short-term strategies without considering longer-term objectives would result to a suboptimal strategy. It would lead to under-invest in expensive, long-to-implement and large-potential options, such as clean transportation infrastructure. To avoid this, existing MAC curves can be enhanced with (1) new graphical representations; (2) improved data collection and reporting concerning the implementation speeds of emission-reduction measures; (3) a simple optimization tool that accounts for constraints on implementation speeds. Climate mitigation policies can be designed through a pragmatic combination of two approaches. A "synergy approach" that uses MAC curves to identify the cheapest mitigation options and maximize co-benefits. And an "urgency approach" which starts from a long-term objective (e.g., halving emissions by 2050) and works backward to identify actions that need to be implemented early. Sector-specific policies may then be used to ensure short-term targets are met without under-investing in the ambitious and long-to-implement abatement measures required to reach long-term targets.
\end{abstract}

Keywords: climate change mitigation policy; low-carbon development plan; carbon lock-in; sectoral policy; technology policy

\footnotetext{
*Corresponding author

Email addresses: vogt@centre-cired.fr (Adrien Vogt-Schilb), shallegatte@worldbank.org (Stéphane Hallegatte), cdegouvello@worldbank.org (Christophe de Gouvello)

We thank Pierre Audinet, Luis Gonzalez, Jean-Charles Hourcade, Pedzi Makumbe, Baptiste Perissin-Fabert and seminar participants at the French Ministère du Développement Durable, Julie Rozenberg, and Supachol Suphachalasai for useful discussions on the work performed here. All remaining errors are the authors' responsibility. We thank the ESMAP (World Bank) for financial support. The views expressed in this paper are the sole responsibility of the authors. They do not necessarily reflect the views of the World Bank, its executive directors, or the countries they represent.
} 


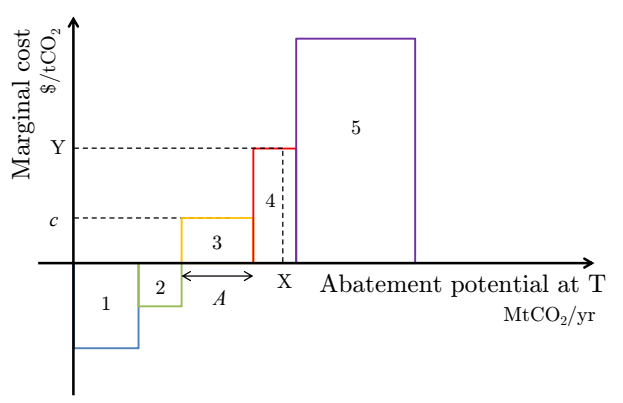

Figure 1: A measure-explicit marginal abatement cost curve. The general appearance of the curve suggests that it is meant to be used as an abatement supply curve, i.e. that the "abatement demand" X should be met by implementing measures 1 to 4 , possibly using the carbon price Y.

Various technical options are available to reduce greenhouse gas (GHG) emissions: fuel switch in the power sector, renewable power, electric vehicles, energy efficiency improvements in combustion engines, waste recycling, forest management, etc. Policy makers have to compare and assess these different options to design a comprehensive mitigation strategy and decide the scheduling of various actions (i.e. decide what measures need to be introduced and when). This is especially true concerning the emission-reduction measures that require government action (e.g., energy-efficiency standards, public investment, public planning).

One tool that has been largely used to assess and compare mitigation actions is the marginal abatement cost (MAC) curve. A MAC curve provides information on abatement costs and abatement potentials for a set of mitigation measures, and ranks them according to their cost, from the least to the most expensive (Fig. 1). MAC curves have proven powerful tools to highlight that large amounts of low-cost emission reductions are technically possible. They also show that some emission reductions can pay for themselves thanks to energy efficiency gains, provided implementation barriers can be overcome (Kesicki and Ekins, 2012). This information can help governments decide about the level of ambition of their mitigation strategy, and make informed domestic and international commitments (in the UNFCCC context, for instance). It is also helpful for policy makers searching for synergies and co-benefits, for instance between emission reductions and economic development.

In addition to its cost and potential, the speed at which an emission-reduction action may be implemented is a key parameter for decision makers. Limited turnover of polluting capital, slow technological diffusion and availability of skilled workers and relevant production lines may all limit the speed at which emission-reduction measures may be implemented. As a consequence, some high-abatement-potential measures, such as switching to renewable power or retrofitting existing energy-inefficient buildings, will take decades to implement.

Vogt-Schilb and Hallegatte (2014) find that this technical inertia ${ }^{1}$ means that optimal short-term action depends drastically on long-term objectives. In

${ }^{1}$ Using the wording by Grubb et al. (1995), Ha-Duong et al. (1997); Lecocq et al. (1998) and Vogt-Schilb et al. (2012). 
particular, it can be optimal to implement more expensive measures before cheaper ones, if the former have a large potential but are long to implement. Moreover, focusing on short-term targets (e.g., for 2030) without considering longer-term objectives (e.g., for 2050 and beyond) could lead to carbon-intensive lock-ins that would make it much more expensive (and potentially impossible) to achieve the long-term objectives.

However, MAC curves do not report information on technical inertia, and thus look like abatement supply curves (e.g. DECC, 2011, fig 17). If MAC curves were supply curves, the optimal emission-reduction strategy would be to "implement the cheapest measure first, preferring measures with a lower total saving potential but more cost-effective than those with a higher GHG saving potential in absolute terms" (Wächter, 2013). To avoid this, Vogt-Schilb and Hallegatte (2014) propose to complement MAC curves with information on implementation speeds, and to use a simple optimization tool to derive optimal strategies taking inertia into account.

In this paper, we test these theoretical findings on a MAC curve built at the World Bank for studying low-carbon development in Brazil in the 20102030 period, and propose improvements to MAC curves. Lack of data beyond 2030 does not allow us to demonstrate that using the 2010-2030 MAC curve to design a mitigation strategy would lead to suboptimal choices in view of longerterm objectives (2050 and beyond). We can however illustrate this problem by assuming that we want to achieve an objective for 2030, and that we use the MAC curve to design a mitigation strategy for the 2010-2020 period only. We find indeed that a strategy for 2010-2020 that disregards the 2030 target under-invests in options such as metro and other transportation infrastructure. Conversely, it over-invests in marginal, cheap but low-potential options, such as heat integration and other improvements in existing refineries.

This work confirms two limits of current MAC curves.

First, MAC curves do not report a very important piece of information, namely the implementation speed of each measure and option. We show however that with marginal modifications, MAC curves could mitigate this problem and better inform decision makers on optimal mitigation strategies. To do so, MAC curves can easily be complemented with information on the speed at which a measure produces abatement results. We propose in Appendix B some guidance for the experts in charge of collecting the information to build a MAC curve, to make sure constraints on implementation speed are collected and reported together with data on costs and potentials. Also, existing and future MAC curves could be presented together with the corresponding emission reduction scenarios or wedge curves (Pacala and Socolow, 2004; Davis et al., 2013), making the dynamic component on the mitigation scenarios more explicit (Fig. 2).

Second, MAC curves are designed for a relatively short term horizon (e.g., 2030), while mitigation objectives go way beyond this horizon. Many countries have longer-term objectives (e.g., the EU has a 2050 objective); and most importantly, tackling climate change and other environmental threats will require to reduce emissions to near-zero levels by the end of the century (e.g., Matthews and Caldeira, 2008; Steinacher et al., 2013). There is no easy way around this problem. Following World Bank (2012, p. 153), we suggest to combine a "synergy approach" based on MAC curves (to identify mitigation options that provide co-benefits in terms of development, economic growth, job creation, local environmental quality, or poverty alleviation) with an "urgency 


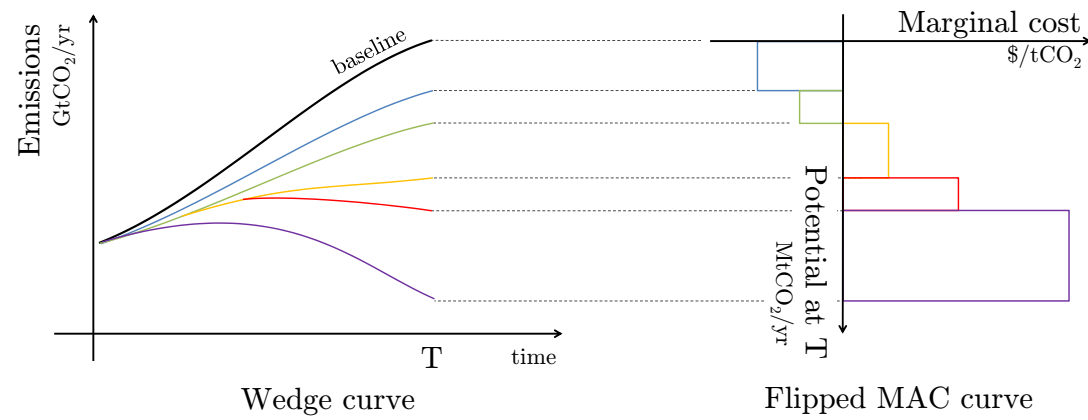

Figure 2: By displaying "flipped" achievable-potential MAC curves nearby the corresponding emission reduction scenarios (wedge curves), confusion on how to interpret MAC curves may be avoided.

approach", based on defining long-term objectives and working backward to identify which measures are needed early to get there on time. In particular, sector-specific policies may be used to ensure global short-term targets are met without under-investing in the ambitious and long-to-implement abatement measures required to achieve otherwise-difficult-to-enforce long-term targets (Hallegatte et al., 2013).

The rest of the paper is structured as follows. In section 1, we review different types of MAC curves. While the construction of MAC curves sometimes requires to investigate the diffusion speed of emission-reduction options, MAC curves do not report separately the long-term abatement potential and the diffusion speed. In section 2, we reanalyze the data from the Brazilian MAC curve and confirm our theoretical results. We also propose a simple optimization model that can be used with this information to compute the least-cost emissionreduction schedule. In section 3 , we conclude and formulate recommendations on the gathering and reporting of data to inform the policy debate on emissionreduction options.

\section{Existing MAC curves}

Measure-explicit MAC curves have been developed since the early 1990s (Rubin et al., 1992), and have reached a wide public after McKinsey and Company published assessments of the cost of abatement potentials in the United States (Enkvist et al., 2007) and at the global scale (McKinsey, 2007). This type of curve is increasingly used to inform policy makers. For instance, McKinsey currently lists MAC curves for 15 different countries or regions on its website. The World Bank also uses MAC curves routinely (ESMAP, 2012), and has recently developed the MACTool to help build such MAC curves (see below). Similar depictions have been used by other institutions (e.g., Climate Works Australia, 2010; NERA and Bloomberg, 2011; CE Delft, 2012) and to analyze other climate-change related topics, such as waste reduction, energy savings and water savings (see Kesicki and Ekins, 2012; Vogt-Schilb and Hallegatte, 2014).

Depending on their implicit definition of the abating potential of a measure, 
two types of measure-explicit MAC curves should be distinguished. ${ }^{2}$

\subsection{Full potential MAC curves}

The full-potential approach gives information on how much GHG could be saved if the measure was used at its technical maximum. It is calculated against a reference or baseline technology, as for instance those used in the present (Wächter, 2013), taking into account the carbon intensity and imperfect substitutability of different technologies. For instance, this approach assesses what fraction of passenger vehicles can be replaced by electric vehicles (EV), accounting for limited driving range and exiting mobility practices. Given emissions from baseline vehicles (e.g $140 \mathrm{~g} / \mathrm{km}$ today in Europe) and emissions from EVs (e.g. none), one can compute an amount of emissions avoidable using electric vehicles. Rubin et al. (1992) use this approach. For instance, they assess the potential of nuclear power (in the US) as the quantity of GHG that would be saved if nuclear replaced all the fossil fuel capacity used for base load and intermediate load operation in 1989 (Table 3, footnote j). In this example, the authors assumed that nuclear power is suited for baseload and intermediate load operation, but not for providing peak power.

The main value of full potential MAC curves is descriptive: they highlight to which extent some key measures could reduce emissions in the long-run. As they do not integrate any consideration on speed, they are not fully operational.

\subsection{Achievable potential MAC curves}

Achievable-potential MAC curves have a prospective dimension, as they are built for a date in the future. This approach fully acknowledges that large-scale diffusion of new technologies can take up to decades (Grübler and Messner, 1998; Grübler et al., 1999; Wilson et al., 2013). In this context, the abating potential of a technology is an assessment of the abatement that could be achieved with such a technology if it was implemented at a given speed, starting at a given date (see for instance McKinsey (2009, p. 46), Pellerin et al. (2013, p. 22)). For instance, this approach takes into account that even ambitious fiscal incentives in favor of electric vehicles would induce a limited increase of EV sales, resulting in a limited share, hence limited emission reductions from EVs by 2020 or 2030. The potential achievable by a given date is therefore lower or equal than the full potential reported on full potential MAC curves.

One weakness of the achievable potential is that it makes the slow diffusion process indistinguishable from the full potential. The reader of a MAC curve does not know if a small potential for abatement from residential building retrofit means that residential buildings are already almost entirely retrofitted in the region (the full potential is low), or it if means that only a small fraction of buildings may be retrofitted during the period (the diffusion is slow).

A key advantage of the achievable-potential approach is that it requires investigating reasonable assumptions regarding the possible implementation speed of a measure (e.g. 1\% of the dwellings can be retrofitted each year). This information is key for a policy maker scheduling emission-reduction investments. Unfortunately, assessed diffusion speeds are not displayed in the resulting MAC curve, and are seldom discussed in the accompanying reports.

2 This classification was first proposed by Vogt-Schilb and Hallegatte (2014) 
The MAC curve we reanalyze in this paper is an achievable-potential MAC curve. In each economic sector, emission reduction scenarios have been assessed taking into account implementation barriers (de Gouvello, 2010).

\subsection{MAC curves at the World Bank: MACTool}

The World Bank develops and promotes a piece of software called MACTool, which can produce achievable-potential MAC curves. One aim of the MACtool is to provide policy makers with a common framework to analyze available mitigation measures. MACTool could become a reference, notably on what is the relevant information that a decision maker requires to take action regarding mitigation plans. MACTool takes as inputs the key socio-technical parameters of a set of large mitigation measures, and macroeconomic variables. For instance, technology options to produce electricity are characterized by required capital and operation expenditures, as well as their lifetime, energy efficiency and type of fuel used. Physical constants as the carbon intensity of each fuel are factored in. The user must also specify at least one scenario on the future macroeconomic variables of interest, such as the price of fossil fuels and the future demand for electricity. Finally, the user must provide scenarios of future penetration of (low-carbon) technologies and measures, in both a baseline and at least one emission-reduction scenario (ESMAP, 2014).

As outputs, MACTool computes the amount of GHG saved by each measure in the long run (in $\mathrm{MtCO}_{2}$ ), and the cost of doing so (in $\$ / \mathrm{tCO}_{2}$ ). This information is illustrated with two figures: an achievable potential MAC curve, and an abatement wedge curve.

The tool itself does not provide information on what is achievable, this information comes directly from the input scenarios. Input scenarios therefore need to be built taking into account the constraints on technology diffusion and implementation speed. For instance, these scenarios may come from models that factor such constraints in, or be built by sector experts who guesstimate possible penetration scenarios (see also Kesicki and Ekins, 2012).

MACTool also reports the investment needed in different emission reduction scenarios. While the abatement costs are computed using the social discount rate entered by the user, MACTool can also compute the carbon price signal that would be required to trigger investments from the private sector, taking into account the opportunity cost of capital for private actors (that is higher than the social discount rate, especially in developing countries).

\section{Proof of concept: Re-analyzing the case of Brazil by 2030}

In a theoretical framework, Vogt-Schilb and Hallegatte (2014) find that focusing on short-term targets and disregarding constraints on implementation speed would lead to suboptimal strategies, making the longer-term target more expensive to reach. In some cases, doing so would even lead to a carbon-intensive lock-ins, making the longer-term target impossible to reach. They develop a simple optimization model to factor implementation speed in the analysis and avoid this problem.

Here, we perform a proof of concept for these ideas, reanalyzing the data used at the World Bank to create a MAC curve for Brazil with MACTool (de Gouvello, 2010). We test the optimization model using proxies and indirect methods 


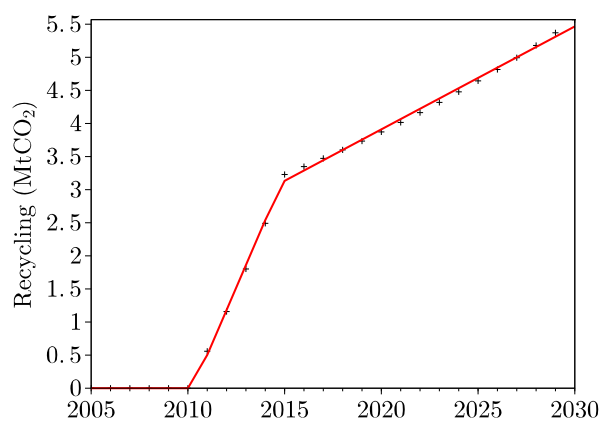

Figure 3: In the data from MACTool, many emission reduction scenarios $(+)$ may be approximated by a piecewise-linear function (red curve). The slope of the first piece provides the diffusion speed for that measure. The second part is interpreted as the maximum potential, that grows over time.

to reconstruct data on implementation speed constraints. Our results confirm the findings of the theoretical paper.

\subsection{Objective}

We take the point of view of a social planner who chooses in 2010 an emissionreduction schedule to comply with an emission target for 2030. We use two simulations.

In the first one, an emission-reduction target is set for year 2030 and an optimal emission strategy is derived, taking into account implementation speed constraints. Then, the abatement obtained in 2020 in this optimal strategy is used as a target for 2020, and the MAC curve is used to design a mitigation strategy between 2010 and 2020, disregarding the longer-term objective.

We then investigate differences of the optimal emission reductions up to 2020 in the two simulations, and confirm the theoretical findings: because of technical inertia, using a MAC curve without taking into account long-term objectives would lead to insufficient short-term investments in options with high potential and slow implementation speed.

\subsection{Methods and data}

We use a spreadsheet program based on the model proposed by Vogt-Schilb and Hallegatte (2014). The program provides the least-cost emission-reduction schedule that complies with the abatement target. As inputs, it requires a list of measures, characterized by a marginal abatement cost, a maximum diffusion speed, and a maximum abatement potential (see Appendix A).

Note that the abatement potential may evolve through time. For instance, if available technology limits intermittent wind power to $20 \%$ of the electricity production and electricity production is expected to grow over time, then the abating potential of wind power grows over time. On the other hand, if natural resources provide only few opportunities to build dams, the abating potential of hydro power is fixed, regardless of total electricity demand growth. We thus extend the model by Vogt-Schilb and Hallegatte (2014) to allow for growing abatement potentials (see below and Appendix A). 


\begin{tabular}{|c|c|c|c|c|}
\hline Measure & $\begin{array}{l}\mathrm{MAC} \\
\$ / \mathrm{tCO}_{2}\end{array}$ & $\begin{array}{c}\text { Diffusion speed } \\
\mathrm{ktCO}_{2} / \mathrm{yr}\end{array}$ & $\begin{array}{c}\text { Potential in } 2010 \\
\mathrm{MtCO}_{2}\end{array}$ & $\begin{array}{c}\text { Potential growth } \\
\mathrm{ktCO}_{2} / \mathrm{yr}\end{array}$ \\
\hline Combustion optimization & -28.4 & 955 & 3.3 & 218 \\
\hline Heat recovery & -59.6 & 168 & 0.6 & 37 \\
\hline Steam recovery & -62.4 & 339 & 1.1 & 77 \\
\hline Furnace heat recovery & -12.8 & 1780 & 8.6 & 743 \\
\hline New processes & 25.8 & 1200 & 4.5 & 265 \\
\hline Other Energy Efficiency & -7.5 & 162 & 0.6 & 35 \\
\hline Thermal Solar & -34.8 & 228 & 0.8 & 50 \\
\hline Recycling & -23.6 & 679 & 2.3 & 155 \\
\hline Natural gas & 0 & 397 & 1.3 & 90 \\
\hline Biomass & 4.3 & 716 & . & . \\
\hline Reforestation & & $\cdot$ & 26.9 & 1002 \\
\hline Wind & 64 & 138 & 1.2 & 0 \\
\hline Comb. Heat Power & -43.2 & 1517 & 5.7 & 241 \\
\hline Solar heat & 83.9 & 18 & . & . \\
\hline Air conditioning & 419.1 & . & 0 & 0 \\
\hline Residential Lightning & -91.9 & . & 0.1 & 0 \\
\hline Cooler & 5.2 & 79 & $\cdot$ & . \\
\hline Motor & -5.8 & 13 & . & . \\
\hline Industrial Lightning & -36.2 & 3 & . & . \\
\hline Commercial lightning & -27.3 & 9 & . & . \\
\hline GTL & 0.6 & 1021 & . & . \\
\hline New Refineries & 16.4 & 352 & . & . \\
\hline Refineries Heat Integration & 10.9 & 510 & 3.1 & 37 \\
\hline Refineries Fouling Mitigation & 45.8 & 59 & 0.5 & 0 \\
\hline Refineries Advanced Control & 79.1 & 59 & 0.5 & 0 \\
\hline Ethanol & 1.8 & 1444 & $\cdot$ & . \\
\hline Rail and Waterways & 23.3 & 494 & $\cdot$ & . \\
\hline Bullet train & 376.3 & 45 & 0.9 & 0 \\
\hline Rapid transit bus & 42 & . & 0 & 0 \\
\hline Metro & 95.7 & 1007 & . & . \\
\hline Traffic optimization & 0.2 & 232 & . & . \\
\hline Bike Lanes & 2.6 & 120 & . & . \\
\hline Solid residues & 2.1 & $\cdot$ & 40.4 & 732 \\
\hline Resid. wastewater & 7.8 & 513 & . & . \\
\hline Indust. Wastewater & 80.4 & . & 8 & 333 \\
\hline Restauration & & 5899 & & . \\
\hline Livestock and Forest & 0.7 & . & 229.4 & 6542 \\
\hline Tilage & -0.2 & 2578 & 17.6 & 185 \\
\hline
\end{tabular}

Table 1: Calibrated speed, cost and potential. A dot $(\cdot)$ denotes lack of reliable data 


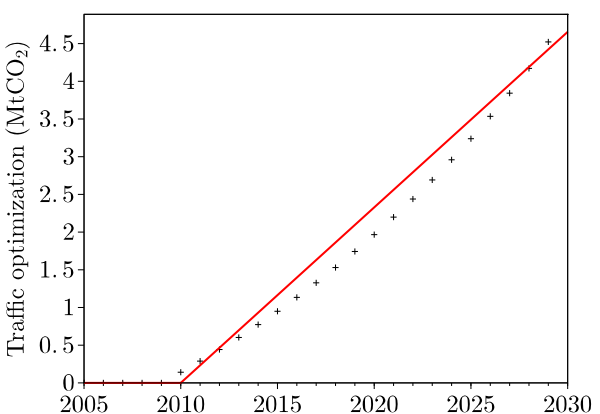

(a) No potential

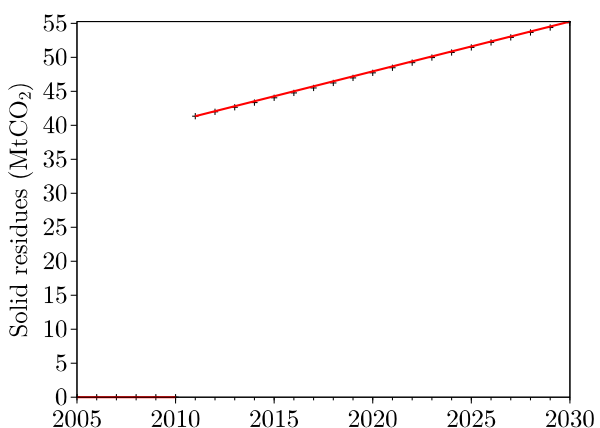

(b) No speed

Figure 4: For some abatement measures, the data needed to calibrate our model cannot be derived from the emission-reduction scenarios provided in MACTool. In some cases (a), the long term potential is not binding, because it cannot be reached before 2030. In some other cases (b), the diffusion speed cannot be assessed (either it was not investigated, or the measure can reach its full potential in less than one year).

We use data collected at the World Bank to build a MAC curve (using MACTool) during a case study on Brazil (de Gouvello, 2010). The MAC curve provides a list of emission-reduction measures, their marginal abatement cost, and the potential achievable by 2030 .

While the list of measures and their cost can be used directly in our spreadsheet program (see the first two columns of Tab. 1), our program requires the full-abatement potential and diffusion speed. Since the diffusion speed and the full-abatement potential were not reported separately, we have to reconstruct it with indirect methods, using the emission-reduction scenarios that were provided to MACTool. For each measure, the shape of the emission-reduction scenarios can be classified in one out of three cases.

In the first case, emission-reduction scenarios may be approximated by a two-phases piecewise-linear function as in Fig. 3. In this case, the diffusion speed is given by the slope of the first piece, and the second phase is interpreted as the growth in full potential. About half the measures fall in this category.

Other emission-reduction scenarios may be approximated by a single linear diffusion (Fig. 4a). In this case, the full potential is not binding before 2030 . We calibrate the diffusion speed from the slope of the penetration pathway, and denote the lack of data on the full potential with a dot (.) in the two last columns of Tab. 1.

In some cases the emission-reduction scenario lacks the first phase; abatement immediately "jumps" to a growing full-potential (Fig. 4b). We denoted them with a dot in the diffusion speed column in Tab. 1. There is usually a handful of such cases in MAC curves exercises. One example from the Brazilian study is solid residues management. In the emission-reduction scenario, solid residues management is able to reduce emissions by more than $40 \mathrm{MtCO}_{2}$ in one year, and then grow at less than $1 \mathrm{MtCO}_{2} / \mathrm{yr}$. From the perspective of the user of a MAC curve, it may be unclear whether this should be considered as a shortcoming in the data (if the investigation could not identify the constraints that limit the diffusion of solid residues management), or a realistic emission- 
reduction scenario (if solid residues management can actually save lots of GHG in a short time lapse). ${ }^{3}$ To avoid this situation in the future, we recommend that the terms of reference for the experts in charge of collecting data on emission reductions options should explicitly ask to report possible diffusion speeds (Appendix B).

Finally, some emission-reduction measures (reforestation, air conditioning and rapid bus transit) were included in the list while lacking either a marginal abatement cost or an emission scenario. These measures, as well as those for which the diffusion speed could not be estimated, are discarded for the rest of the analysis. The remaining options allow to reduce Brazilian emissions in 2030 by $223 \mathrm{MtCO}_{2}$ (compared with $812 \mathrm{MtCO}_{2}$ in the original MAC curve).

\subsection{Optimal strategy with a 2030 objective}

In a first simulation, we run our spreadsheet model to design the optimal strategy to achieve $223 \mathrm{MtCO}_{2}$ of emission reductions by 2030 (Tab. 2). The optimal emission-reduction strategy has the following characteristics.

All negative-cost measures are introduced at full speed from year 2010, independently of the emission-reduction target. This simply reflects that these measures are desirable per se, as they bring more benefits than costs even in the absence of any carbon pricing or climate change impacts.

For the positive-cost measures, the least-cost strategy is to implement them as late as possible, to benefit from the discount rate. This means that under an emission-reduction target in one point in time, such as $-30 \%$ by 2030 , the twophase penetration pictured in Fig. 3 is not optimal for positive-cost measures. A better solution is to delay the implementation such that the maximum potential is reached just in time, when the target needs to be achieved. ${ }^{4}$

\subsection{Strategy with a 2020 objective}

The optimal emission reduction pathway to achieve $223 \mathrm{MtCO}_{2}$ in 2030 leads to $127 \mathrm{MtCO}_{2}$ of emission reductions in 2020 (Tab. 2). To investigate how focusing on short-term targets may lead to suboptimal outcomes, we run a second simulation with the only constraint of reducing emissions by $127 \mathrm{MtCO}_{2}$ in 2020 , and we investigate the "optimal" solution provided by our model in this case (Tab. 3). In line with Vogt-Schilb and Hallegatte (2014), the least-cost strategy for 2010-2020 uses different emission-reduction options, depending on whether the strategy aims at a short-term target $\left(127 \mathrm{MtCO}_{2}\right.$ in 2020$)$ or at a longerterm one $\left(223 \mathrm{MtCO}_{2}\right.$ in 2030). The simulation that ends in 2020 uses notably less investment in metro and other clean transportation infrastructure, and more

\footnotetext{
${ }^{3}$ Livestock and forest management is a particular example. In the emission-reduction scenarios, this measures allows to save $229 \mathrm{MtCO}_{2}$, that is almost one third of the total abatement potential by 2030, as soon as 2010. Since Brazil has already managed to reduce drastically its emissions from deforestation (-80\% between 2004 and 2009$)$, the study considered that this mitigation option is already enforced. Sustaining such effort over a long period will require to ensure that productivity gains in the livestock sector free-up pasture land fast enough to accommodate the growth of the livestock-agriculture sector without deforesting, as recommended in the Brazil Low-carbon study (de Gouvello, 2010). Such dissemination will face a similar inertia issue; however, this is a slightly different discussion.

${ }^{4}$ If the climate mitigation target was expressed in terms of a carbon budget (consistently with climate change physics, Zickfeld et al., 2009), then the two-phase penetration target would be optimal (Vogt-Schilb and Hallegatte, 2014, section 4).
} 


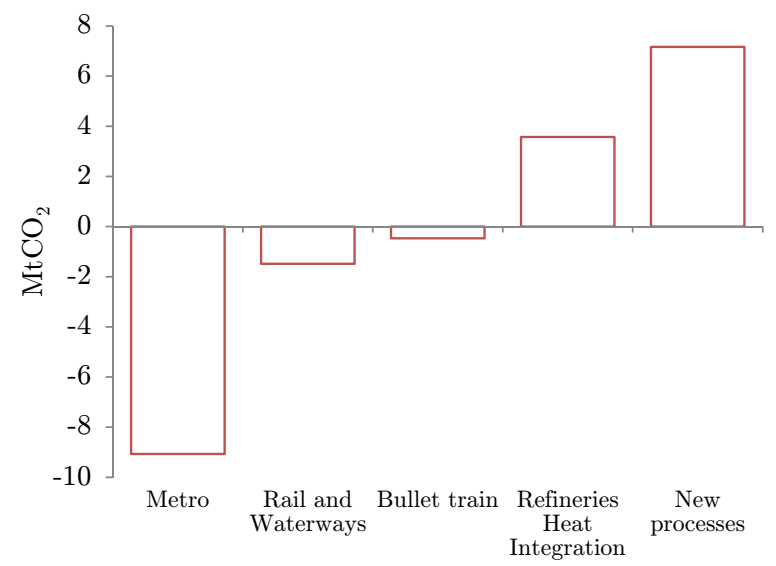

Figure 5: Bias from short-term (2020) time horizon compared with optimal longterm (2030) strategy. On the positive side, measures are used excessively in the 2020 strategy, compared to what they should be used to reach the 2030 target; on the negative side, measures are used insufficiently. Only the 5 larger absolute differences are shown.

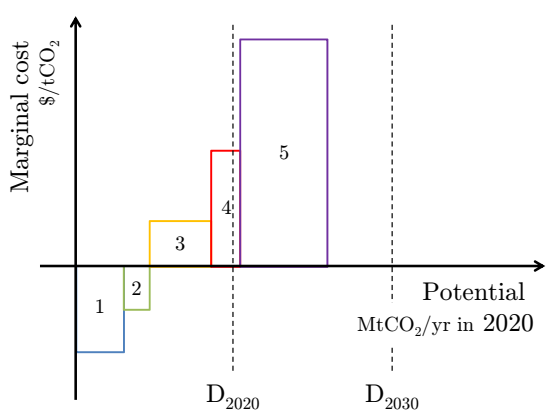

(a) Achievable by 2020

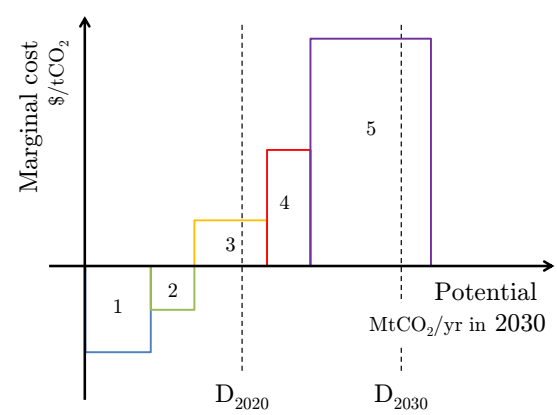

(b) Achievable by 2030

Figure 6: In this example, the 2020 MAC curve (a) suggests that the 2020 target $\left(D_{2020}\right)$ should be met with options 1-4, disregarding option 5 before 2020 . But then only a fraction of option 5 could be implemented between 2020 and 2030 . The 2030 MAC curve (b) however shows that options 1-5 should be implemented by 2030 to meet the $D_{2030}$ target. For option 5 to deliver all the abatement listed by 2030, it should be implemented before 2020. A MAC curve built for longer-term horizons (e.g. 2050) would show that even more options should be deployed early. 


\begin{tabular}{|c|c|c|c|c|c|c|c|c|c|c|c|}
\hline & 2010 & 2011 & 2012 & 2013 & 2014 & 2015 & 2016 & 2017 & 2018 & 2019 & 2020 \\
\hline Combustion optimization & 0.96 & 1.91 & 2.87 & 3.82 & 4.19 & 4.41 & 4.63 & 4.84 & 5.06 & 5.28 & 5.50 \\
\hline Heat recovery & 0.17 & 0.34 & 0.51 & 0.67 & 0.78 & 0.82 & 0.86 & 0.90 & 0.93 & 0.97 & 1.01 \\
\hline Steam recovery & 0.34 & 0.68 & 1.02 & 1.36 & 1.49 & 1.56 & 1.64 & 1.72 & 1.80 & 1.87 & 1.95 \\
\hline Furnace heat recovery & 1.78 & 3.56 & 5.34 & 7.12 & 8.90 & 10.69 & 12.47 & 13.84 & 14.58 & 15.32 & 16.07 \\
\hline New processes & - & - & - & - & - & - & - & - & - & - & - \\
\hline Other Energy Efficiency & 0.16 & 0.33 & 0.49 & 0.65 & 0.75 & 0.79 & 0.83 & 0.86 & 0.90 & 0.93 & 0.97 \\
\hline Thermal Solar & 0.23 & 0.46 & 0.68 & 0.91 & 1.06 & 1.11 & 1.16 & 1.21 & 1.26 & 1.31 & 1.36 \\
\hline Recycling & 0.68 & 1.36 & 2.04 & 2.72 & 2.98 & 3.13 & 3.29 & 3.44 & 3.60 & 3.76 & 3.91 \\
\hline Natural gas & 0.40 & 0.79 & 1.19 & 1.59 & 1.74 & 1.83 & 1.92 & 2.01 & 2.10 & 2.20 & 2.29 \\
\hline Biomass & 0.72 & 1.43 & 2.15 & 2.87 & 3.58 & 4.30 & 5.02 & 5.73 & 6.45 & 7.17 & 7.89 \\
\hline Wind & - & - & - & - & - & - & - & - & - & - & - \\
\hline Comb. Heat Power & 1.52 & 3.04 & 4.55 & 6.07 & 6.68 & 6.92 & 7.16 & 7.40 & 7.64 & 7.88 & 8.13 \\
\hline Solar heat & 0.02 & 0.04 & 0.06 & 0.07 & 0.09 & 0.11 & 0.13 & 0.15 & 0.17 & 0.18 & 0.20 \\
\hline Cooler & 0.08 & 0.16 & 0.24 & 0.32 & 0.40 & 0.48 & 0.56 & 0.64 & 0.71 & 0.79 & 0.87 \\
\hline Motor & 0.01 & 0.03 & 0.04 & 0.05 & 0.07 & 0.08 & 0.09 & 0.11 & 0.12 & 0.13 & 0.15 \\
\hline Industrial Lightning & 0.00 & 0.01 & 0.01 & 0.02 & 0.02 & 0.02 & 0.03 & 0.03 & 0.03 & 0.04 & 0.04 \\
\hline Commercial lightning & 0.01 & 0.02 & 0.03 & 0.04 & 0.05 & 0.06 & 0.07 & 0.07 & 0.08 & 0.09 & 0.10 \\
\hline GTL & 1.02 & 2.04 & 3.06 & 4.09 & 5.11 & 6.13 & 7.15 & 8.17 & 9.19 & 10.21 & 11.24 \\
\hline New Refineries & 0.35 & 0.70 & 1.06 & 1.41 & 1.76 & 2.11 & 2.47 & 2.82 & 3.17 & 3.52 & 3.87 \\
\hline Refineries Heat Integration & - & - & - & - & - & - & - & - & - & - & - \\
\hline Refineries Fouling Mitigation & - & - & - & - & - & - & - & - & - & - & - \\
\hline Refineries Advanced Control & - & - & - & - & - & - & - & - & - & - & - \\
\hline Ethanol & 1.44 & 2.89 & 4.33 & 5.78 & 7.22 & 8.67 & 10.11 & 11.56 & 13.00 & 14.44 & 15.89 \\
\hline Rail and Waterways & 0.49 & 0.99 & 1.48 & 1.98 & 2.47 & 2.97 & 3.46 & 3.96 & 4.45 & 4.95 & 5.44 \\
\hline Bullet train & 0.01 & 0.06 & 0.10 & 0.15 & 0.19 & 0.24 & 0.28 & 0.33 & 0.38 & 0.42 & 0.47 \\
\hline Metro & 1.01 & 2.02 & 3.02 & 4.03 & 5.04 & 6.05 & 7.05 & 8.06 & 9.07 & 10.08 & 11.09 \\
\hline Traffic optimization & 0.23 & 0.47 & 0.70 & 0.93 & 1.16 & 1.40 & 1.63 & 1.86 & 2.10 & 2.33 & 2.56 \\
\hline Bike Lanes & 0.12 & 0.24 & 0.36 & 0.48 & 0.60 & 0.72 & 0.84 & 0.97 & 1.09 & 1.21 & 1.33 \\
\hline Resid. wastewater & 0.51 & 1.03 & 1.54 & 2.05 & 2.57 & 3.08 & 3.59 & 4.11 & 4.62 & 5.13 & 5.65 \\
\hline Tilage & 2.58 & 5.16 & 7.74 & 10.31 & 12.89 & 15.47 & 18.05 & 18.91 & 19.09 & 19.28 & 19.46 \\
\hline
\end{tabular}




\begin{tabular}{|c|c|c|c|c|c|c|c|c|c|c|c|}
\hline & 2010 & 2011 & 2012 & 2013 & 2014 & 2015 & 2016 & 2017 & 2018 & 2019 & 2020 \\
\hline Combustion optimization & 0.96 & 1.91 & 2.87 & 3.82 & 4.19 & 4.41 & 4.63 & 4.84 & 5.06 & 5.28 & 5.50 \\
\hline Heat recovery & 0.17 & 0.34 & 0.51 & 0.67 & 0.78 & 0.82 & 0.86 & 0.90 & 0.93 & 0.97 & 1.01 \\
\hline Steam recovery & 0.34 & 0.68 & 1.02 & 1.36 & 1.49 & 1.56 & 1.64 & 1.72 & 1.80 & 1.87 & 1.95 \\
\hline Furnace heat recovery & 1.78 & 3.56 & 5.34 & 7.12 & 8.90 & 10.69 & 12.47 & 13.84 & 14.58 & 15.32 & 16.07 \\
\hline New processes & - & - & - & - & - & 1.16 & 2.36 & 3.56 & 4.77 & 5.97 & 7.17 \\
\hline Other Energy Efficiency & 0.16 & 0.33 & 0.49 & 0.65 & 0.75 & 0.79 & 0.83 & 0.86 & 0.90 & 0.93 & 0.97 \\
\hline Thermal Solar & 0.23 & 0.46 & 0.68 & 0.91 & 1.06 & 1.11 & 1.16 & 1.21 & 1.26 & 1.31 & 1.36 \\
\hline Recycling & 0.68 & 1.36 & 2.04 & 2.72 & 2.98 & 3.13 & 3.29 & 3.44 & 3.60 & 3.76 & 3.91 \\
\hline Natural gas & 0.40 & 0.79 & 1.19 & 1.59 & 1.74 & 1.83 & 1.92 & 2.01 & 2.10 & 2.20 & 2.29 \\
\hline Biomass & 0.72 & 1.43 & 2.15 & 2.87 & 3.58 & 4.30 & 5.02 & 5.73 & 6.45 & 7.17 & 7.89 \\
\hline Wind & - & - & - & - & - & - & - & - & 0.14 & 0.28 & 0.41 \\
\hline Comb. Heat Power & 1.52 & 3.04 & 4.55 & 6.07 & 6.68 & 6.92 & 7.16 & 7.40 & 7.64 & 7.88 & 8.13 \\
\hline Solar heat & - & - & - & - & - & - & - & - & - & 0.02 & 0.04 \\
\hline Cooler & 0.08 & 0.16 & 0.24 & 0.32 & 0.40 & 0.48 & 0.56 & 0.64 & 0.71 & 0.79 & 0.87 \\
\hline Motor & 0.01 & 0.03 & 0.04 & 0.05 & 0.07 & 0.08 & 0.09 & 0.11 & 0.12 & 0.13 & 0.15 \\
\hline Industrial Lightning & 0.00 & 0.01 & 0.01 & 0.02 & 0.02 & 0.02 & 0.03 & 0.03 & 0.03 & 0.04 & 0.04 \\
\hline Commercial lightning & 0.01 & 0.02 & 0.03 & 0.04 & 0.05 & 0.06 & 0.07 & 0.07 & 0.08 & 0.09 & 0.10 \\
\hline GTL & 1.02 & 2.04 & 3.06 & 4.09 & 5.11 & 6.13 & 7.15 & 8.17 & 9.19 & 10.21 & 11.24 \\
\hline New Refineries & - & 0.35 & 0.70 & 1.06 & 1.41 & 1.76 & 2.11 & 2.47 & 2.82 & 3.17 & 3.52 \\
\hline Refineries Heat Integration & - & - & - & - & 0.51 & 1.02 & 1.53 & 2.04 & 2.55 & 3.06 & 3.57 \\
\hline Refineries Fouling Mitigation & - & - & - & - & - & - & - & 0.06 & 0.12 & 0.18 & 0.24 \\
\hline Refineries Advanced Control & - & - & - & - & - & - & - & - & 0.03 & 0.09 & 0.15 \\
\hline Ethanol & 1.44 & 2.89 & 4.33 & 5.78 & 7.22 & 8.67 & 10.11 & 11.56 & 13.00 & 14.44 & 15.89 \\
\hline Rail and Waterways & - & - & - & 0.49 & 0.99 & 1.48 & 1.98 & 2.47 & 2.97 & 3.46 & 3.96 \\
\hline Bullet train & - & - & - & - & - & - & - & - & - & - & - \\
\hline Metro & - & - & - & - & - & - & - & - & - & 1.01 & 2.02 \\
\hline Traffic optimization & 0.23 & 0.47 & 0.70 & 0.93 & 1.16 & 1.40 & 1.63 & 1.86 & 2.10 & 2.33 & 2.56 \\
\hline Bike Lanes & 0.12 & 0.24 & 0.36 & 0.48 & 0.60 & 0.72 & 0.84 & 0.97 & 1.09 & 1.21 & 1.33 \\
\hline Resid. wastewater & 0.51 & 1.03 & 1.54 & 2.05 & 2.57 & 3.08 & 3.59 & 4.11 & 4.62 & 5.13 & 5.65 \\
\hline Tilage & 2.58 & 5.16 & 7.74 & 10.31 & 12.89 & 15.47 & 18.05 & 18.91 & 19.09 & 19.28 & 19.46 \\
\hline
\end{tabular}


heat integration and other marginal improvements in existing refineries (Fig. 5). Clean transportation infrastructure is characterized by a large abatement potential, high and lumpy upfront costs, and large inertia (Framstad and Strand, 2013; Kopp et al., 2013; Lecocq and Shalizi, 2014). In the long-term target scenario, clean transportation is implemented as fast as possible. In the shortterm target scenario for 2020, it is replaced by cheaper and faster-to-implement measures (see also Fig. 6).

The short-term target masks the longer-term target, such that long-toimplement options required in the long term are not promoted soon enough. In this example, reaching the 2030 target requires to implement 95 additional $\mathrm{MtCO}_{2}$ between 2020 and 2030. However, a 2020-2030 strategy would be able to save $84 \mathrm{MtCO}_{2}$ additionally at best, since not enough time would be left to deploy time intensive solutions. This new low-carbon scenario would therefore be short $11 \mathrm{MtCO}_{2}$ or $12 \%$ in 2030 compared to the first one. In other words, the 2030 target becomes impossible to achieve after 2020, as the limited diffusion speed prevents high-abatement-potential options to achieve their optimal 2030 level in 10 years.

\section{Conclusion}

This paper confirms with a case study on Brazil the theoretical findings from Vogt-Schilb and Hallegatte (2014). Limited implementation speed of emissionreduction measures means that optimal short-term action critically depends on long-term objectives. Using a MAC curve to design a mitigation strategy for the 2010-2020 period without accounting for a longer-term goal for 2030 would thus lead to insufficient investments in options with low implementation speed and large abatement potential. In the Brazilian case, it would lead to less investment in clean transportation infrastructure (metro, bullet train, rail and waterways), and more investment in marginal improvements of existing refineries by 2020. This would even lead to a lock-in in carbon-intensive patterns, making it impossible for a subsequent 2020-2030 strategy to reach the 2030 target, as better transportation infrastructure is critical to reduce emissions on the long term.

These results suggest that using a 2030 MAC curve to plan a mitigation strategy that has a long-term objective (for 2050 and beyond) will lead to similar issues, namely under-investment in some of the most important mitigation options and a carbon lock-in.

We propose a few solutions to this problem.

First, to avoid their misinterpretation as abatement supply curves, achievable MAC curves could be displayed together with the corresponding emissionreduction scenario, also known as wedge curve (Fig. 2). This graphical interpretation makes it explicit that MAC curves are built from emission scenarios, and in particular that it takes time to achieve the achievable potential.

Second, the example studied here indicates that the abatement potential and the abatement cost are not sufficient information to schedule emission reduction. The implementation speed is instrumental to investigating emission-reduction strategies, and should explicitly be investigated and reported separately from the achievable potential (Appendix B).

Third, our simulations suggest that aggregated short-term abatement targets may be misleading. An ideal policy would be to announce well in advance 
a perfectly credible long-term target to a forward-looking market. In practice, however, governments have limited ability to commit, and markets cannot perfectly anticipate future regulations (Brunner et al., 2012). Short-term sectoror even technology-specific policies may in this case be re-thought as supplements to aggregated short-term abatement targets. ${ }^{5}$ They can indeed ensure that aggregated short-term targets are met with some of the expensive, highabatement and long-to-implement measures required to reach the long-term target in a cost-effective manner.

Finally, the long-term cost, abatement potential and diffusion speed of emission reduction measures is subject to large uncertainties (e.g., regarding the potential for cost reduction due to learning by doing). We thus recommend to combine a "synergy approach" with an "urgency approach" when designing mitigation strategies (re-framing the suggestion in World Bank, 2012, p. 153). The synergy approach identifies the cheapest mitigation options, and those that provide co-benefits in terms of development, economic growth, job creation, local environmental quality, or poverty alleviation.

The urgency approach considers the long-term objective (e.g., halving emissions by 2050, or achieving carbon neutrality in 2100) and works backward to identify actions that need to be implemented early to make it possible to reach that goal, even when these actions are costly of difficult to implement. Various policies can then be implemented, for instance combining a carbon price to capture low-cost abatement opportunity (e.g., through a carbon tax) with regulations or direct investment to trigger actions where anticipation is critical (e.g., with urban land-use plans, infrastructure, and the development of zero-carbon technologies for the power or transportation sectors).

\section{References}

Brunner, S., Flachsland, C., Marschinski, R., 2012. Credible commitment in carbon policy. Climate Policy 12 (2), 255-271.

CE Delft, 2012. Marginal abatement cost curves for heavy duty vehicles. Background report, Arno Schroten, Geert Warringa and Mart Bles, Delft.

Climate Works Australia, 2010. Low carbon growth plan for Australia. ClimateWorks Australia Clayton.

Davis, S. J., Cao, L., Caldeira, K., Hoffert, M. I., 2013. Rethinking wedges. Environmental Research Letters 8 (1), 011001.

de Gouvello, C., 2010. Brazil Low-carbon Country Case Study. The World Bank, Washington DC, USA.

DECC, 2011. Impact assessment of fourth carbon budget level. Impact Assessment DECC0054, Department of Energy and Climate Change, UK.

\footnotetext{
5 To date, such policies have been assessed as a way to tackle several market failures or policy objectives (Sandén and Azar, 2005; Fischer and Preonas, 2010), to complement an imperfect carbon-pricing mechanism (Lecuyer and Quirion, 2013), to correct for the effects of misperceived energy savings (Tsvetanov and Segerson, 2013; Parry et al., 2014), or as a political economy constraint (Rozenberg et al., 2013; Jenkins, 2014). Jenkins (2014) provides a recent review.
} 
Enkvist, P., Nauclér, T., Rosander, J., 2007. A cost curve for greenhouse gas reduction. McKinsey Quarterly 1, 34 .

ESMAP, 2012. Planning for a low carbon future: Lessons learned from seven country studies. Knowledge series 011/12, Energy Sector Management Assistance Program - The World Bank, Washington DC, USA.

ESMAP, 2014. Modeling tools and e-learning: MACTool. URL http://esmap.org/MACTool

Fischer, C., Preonas, L., 2010. Combining policies for renewable energy: Is the whole less than the sum of its parts? International Review of Environmental and Resource Economics 4, 51-92.

Framstad, N. C., Strand, J., 2013. Energy intensive infrastructure investments with retrofits in continuous time: Effects of uncertainty on energy use and carbon emissions. World bank policy research working paper, 6430.

Grübler, A., Messner, S., 1998. Technological change and the timing of mitigation measures. Energy Economics 20 (5-6), 495-512.

Grübler, A., Nakićenović, N., Victor, D. G., 1999. Dynamics of energy technologies and global change. Energy policy 27 (5), 247-280.

Grubb, M., Chapuis, T., Ha-Duong, M., 1995. The economics of changing course: Implications of adaptability and inertia for optimal climate policy. Energy Policy 23 (4-5), pp. 417-431.

Ha-Duong, M., Grubb, M., Hourcade, J., 1997. Influence of socioeconomic inertia and uncertainty on optimal CO2-emission abatement. Nature 390 (6657), 270-273.

Hallegatte, S., Fay, M., Vogt-Schilb, A., 2013. Green industrial policies: When and how. World Bank Policy Research Working Paper (6677).

Jenkins, J. D., 2014. Political economy constraints on carbon pricing policies: What are the implications for economic efficiency, environmental efficacy, and climate policy design? Energy Policy.

Kesicki, F., Ekins, P., 2012. Marginal abatement cost curves: a call for caution. Climate Policy 12 (2), 219-236.

Kopp, A., Block, R. I., Iimi, A., May 2013. Turning the Right Corner: Ensuring Development through a Low-Carbon Transport Sector. The World Bank.

Lecocq, F., Hourcade, J., Ha Duong, M., 1998. Decision making under uncertainty and inertia constraints: sectoral implications of the when flexibility. Energy Economics 20 (5-6), 539-555.

Lecocq, F., Shalizi, Z., 2014. The economics of targeted mitigation in infrastructure. Climate Policy 14 (2), 187-208.

Lecuyer, O., Quirion, P., 2013. Can uncertainty justify overlapping policy instruments to mitigate emissions? Ecological Economics 93, 177-191. 
Matthews, H. D., Caldeira, K., 2008. Stabilizing climate requires near-zero emissions. Geophysical Research Letters 35 (4).

McKinsey, 2007. Reducing US greenhouse gas emissions: How much at what cost? Tech. rep., McKinsey \& Company.

McKinsey, 2009. Pathways to a low-carbon economy: Version 2 of the global greenhouse gas abatement cost curve. Tech. rep., McKinsey \& Company.

NERA, Bloomberg, 2011. The demand for greenhouse gas emissions reduction investments: An investors' marginal abatement cost curve for Kazakhstan. Prepared for the European Bank for Reconstruction and Development, NERA Economic Consulting and Bloomberg New Energy Finance.

Pacala, S., Socolow, R., 2004. Stabilization wedges: Solving the climate problem for the next 50 years with current technologies. Science 305 (5686), 968-972.

Parry, I. W. H., Evans, D., Oates, W. E., 2014. Are energy efficiency standards justified? Journal of Environmental Economics and Management 67 (2), 104 125.

Pellerin, S., Bamière, L., Angers, D., Béline, F., Benoît, M., Butault, J., Chenu, C., Colnenne-David, C., De Care, S., Delame, N., Doreau, M., Dupraz, P., Faverdin, P., Garcia-Launay, F., Hassouna, M., Hénault, C., Jeuffroy, M., Klumpp, K., Metay, A., Moran, D., Recous, S., Samson, E., Savini, I., Pardon, L., 2013. Quelle contribution de l'agriculture française à la réduction des émissions de gaz à effet de serre? Potentiel d'atténuation et coût de dix actions techniques. Synthèse du rapport d'étude, INRA, France.

Rozenberg, J., Vogt-Schilb, A., Hallegatte, S., 2013. How capital-based instruments facilitate the transition toward a low-carbon economy: a tradeoff between optimality and acceptability. World Bank Policy Research Working Paper (6609).

Rubin, E. S., Cooper, R. N., Frosch, R. A., Lee, T. H., Marland, G., Rosenfeld, A. H., Stine, D. D., 1992. Realistic mitigation options for global warming. Science 257 (5067), 148-149.

Sandén, B. A., Azar, C., 2005. Near-term technology policies for long-term climate targets - economy wide versus technology specific approaches. Energy Policy 33 (12), 1557-1576.

Steinacher, M., Joos, F., Stocker, T. F., 2013. Allowable carbon emissions lowered by multiple climate targets. Nature 499 (7457), 197-201.

Tsvetanov, T., Segerson, K., 2013. Re-evaluating the role of energy efficiency standards: A behavioral economics approach. Journal of Environmental Economics and Management 66 (2), 347-363.

Vogt-Schilb, A., Hallegatte, S., 2014. Marginal abatement cost curves and the optimal timing of mitigation measures. Energy Policy 66, 645-653.

Vogt-Schilb, A., Meunier, G., Hallegatte, S., 2012. How inertia and limited potentials affect the timing of sectoral abatements in optimal climate policy. World Bank Policy Research Working Paper 6154. 
Wächter, P., 2013. The usefulness of marginal CO2-e abatement cost curves in Austria. Energy Policy 61, 1116-1126.

Wilson, C., Grubler, A., Bauer, N., Krey, V., Riahi, K., 2013. Future capacity growth of energy technologies: are scenarios consistent with historical evidence? Climatic Change 118 (2), 381-395.

World Bank, 2012. Inclusive green growth : the pathway to sustainable development. World Bank, Washington, D.C.

Zickfeld, K., Eby, M., Matthews, H. D., Weaver, A. J., 2009. Setting cumulative emissions targets to reduce the risk of dangerous climate change. Proceedings of the National Academy of Sciences 106 (38), 16129-16134.

\section{Appendix A. Model}

We extend the model proposed by Vogt-Schilb and Hallegatte (2014).

The quantity of emission reductions done with measure $i$ at time $t$ is denoted $a_{i, t}$. The abatement potential of measure $i$ is denoted $A_{i, t}$, imposing the following constraint: ${ }^{6}$

$$
\forall(i, t), a_{i, t} \leq A_{i, t}
$$

The second constraint on emission reduction is that they cannot grow faster than the diffusion speed $v_{i}$, such that:

$$
a_{i, t+1} \leq a_{i, t}+v_{i}
$$

The abatement target, set for a date in the future $T$ (e.g. 2020 or 2030), is denoted $a_{T}^{\star}$. It sets the following constraint:

$$
\sum_{i} a_{i, T} \geq a_{T}^{\star}
$$

Taking the discount rate $r$ as given, the model computes the least-cost emission reduction schedule, where the cost of measure $i$ is $c_{i}$ :

$$
\min _{a_{i, t}} \sum_{i, t} e^{-r t} c_{i} a_{i, t}
$$

An Excel implementation of this model is available online.

\section{Appendix B. Information collection guidance}

The following proposes guidance on how data on emission reduction measures could be collected to take into account the findings of this paper. The objective is to collect data that can be used to build MAC curves as usual, and also to inform a prescriptive model. Asking specifically to disclosure assumptions

\footnotetext{
${ }^{6}$ In the model proposed by Vogt-Schilb and Hallegatte (2014), abatement potentials do not evolve over time. This is the only extension we propose.
} 
on speed (3c) should help identify bottlenecks preventing some measures to be implemented. Also, collecting this data does not require more work that what is currently done to build MAC curves; clarifying the difference between implementation speed and full technical potential may actually facilitate the data-gathering process.

Of course, this sketch should be adapted to local conditions; for instance, it should account for existing plans and projections when defining emission baseline and abatement potentials.

1. Inventory of existing GHG emissions

(a) Provide the list of GHG emissions at a given date in the recent past. Chose the most recent date for which data is available .

(b) Provide a breakdown of these emissions by sector, e.g. power generation, industry, residential sector, transportation, agriculture. Use sub-sectors where possible, for instance as provided by ISI.

(c) Provide information of the output of such sectors.

i. Use physical measures of output when possible, e.g:

A. In the transportation sector, use passenger-kilometer and ton-kilometer.

B. In the power sector, use MWh.

C. In the residential sector, use number of inhabitants at given comfort.

ii. Express these emissions in $\mathrm{CO}_{2}$ equivalent using accepted conversion factors.

2. Prospective : provide projections of future GHG emissions reported in 1 using the same breakdown.

3. List available emission-reduction measures

(a) Full technological potentials

i. Provide emission-intensity of each activity.

ii. Provide maximum penetration rate with today's technology: e.g. hydro power limited by river availability, electric vehicles limited by range. If relevant provide maximum penetration rate given political and societal constraints (e.g. if nuclear power is unacceptable).

(b) Costs

i. Report Capex and Opex separately

A. Report input-efficiency (e.g. fuel-efficiency and fuel type)

B. Report input prices (report taxes separatedly)

ii. Report domestic and foreign expenses separately.

iii. Report costs used to pay domestic salaries separately

For instance, a photovoltaic power module can be imported but the installation is paid to a local worker; avoided gasoline use from electric vehicles means less oil imports, but also less tax revenue.

(c) Speed at which new technologies may enter the market. This piece of data assesses the speed at which each option can be implemented taking into account the required accumulation of human and physical capital.

i. Report typical capital lifetimes for considered technologies and related technologies in the sector - e.g. cars typically live 12 years. 
ii. Report past penetration rates for similar technologies in the sector - e.g. diesel sales took 30 years to go from 0 to $50 \%$ in the past.

iii. Report current bottlenecks (institutional barriers, available resources) - e.g. available workforce can retrofit 100000 dwellings per year. 